
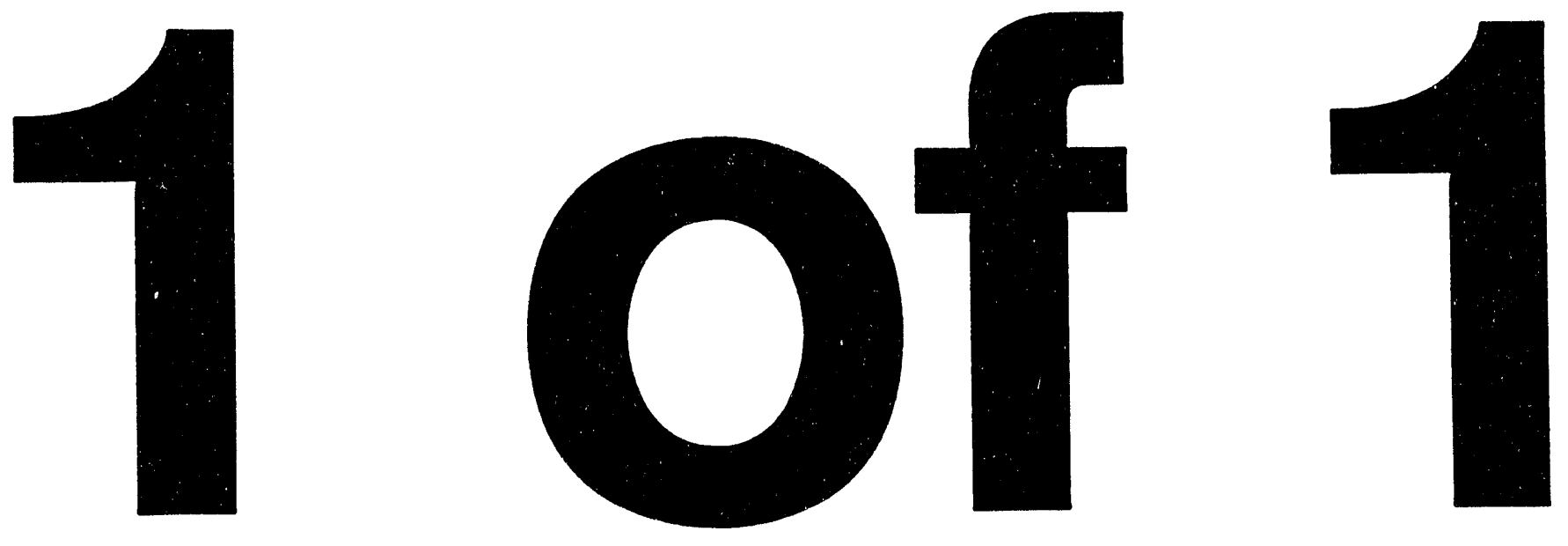
UCRL- JC- 116836

PREPRINT

\section{EBIT X-ray Spectroscopy Studies for Applications to Photo-Pumped X-ray Lasers}

\author{
S. R. Elliott \\ P. Beiersdorfer \\ J. Nilsen \\ Prepared for Submittal to \\ 4th International Colloquium on X-Ray Lasers \\ Williamsburg, Virginia \\ May 16-20, 1994
}

May 10, 1994

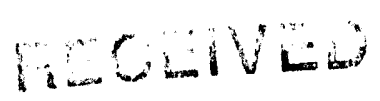

OSTI

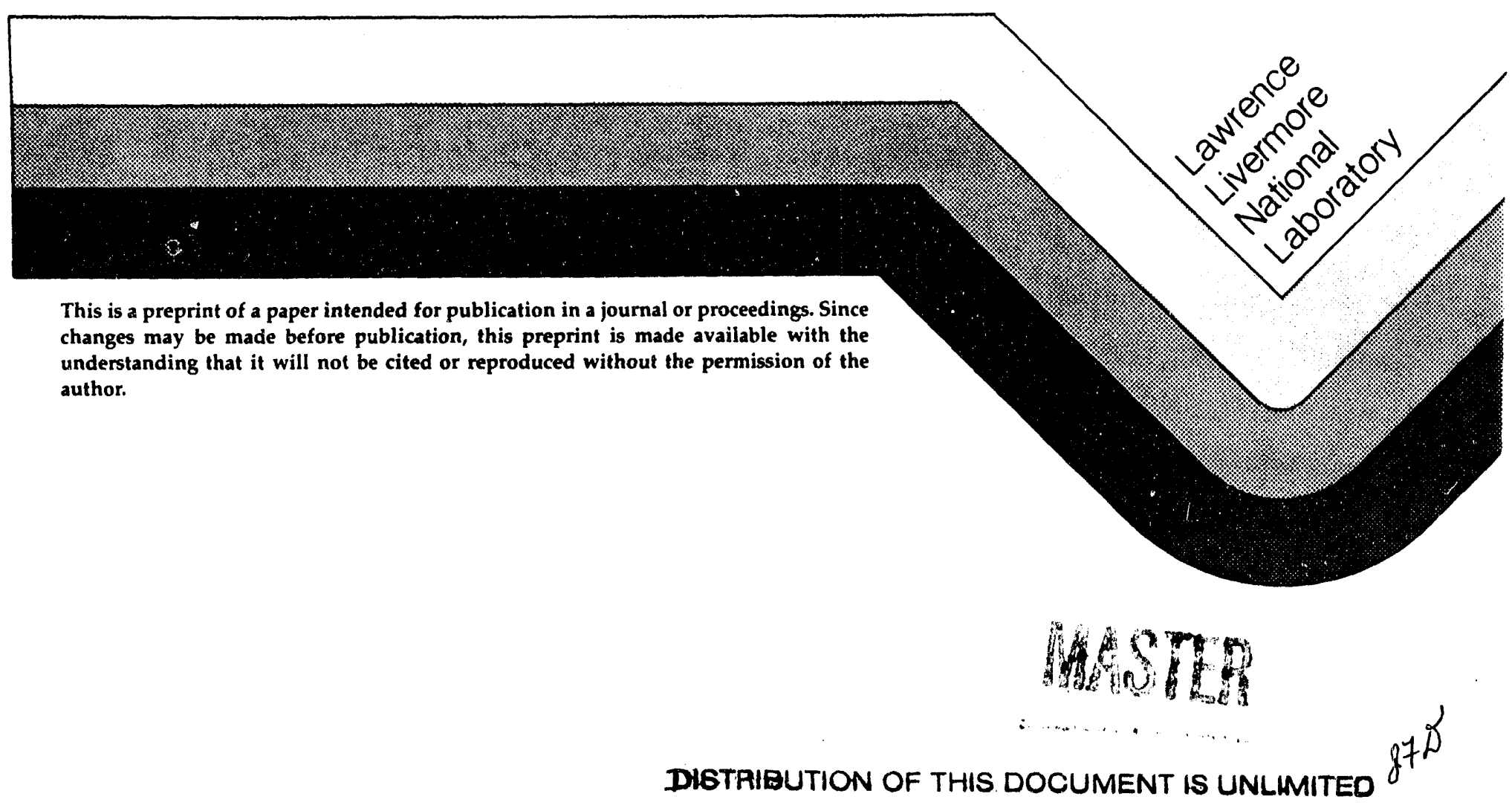




\section{DISCLAIMER}

This document was prepared as an account of work sponsored by an agency of the United States Government. Neither the United States Government nor the University of California nor any of their employees, makes any warranty, express or implied, or assumes any legal liability or responsibility for the accuracy, completeness, or usefulness of any information, apparatus, product, or process disclosed, or represents that its use would not infringe privately owned rights. Reference herein to any specific commercial product, process, or service by trade name, trademark, manufacturer, or otherwise, does not necessarlly constitute or imply its endorsement, recommendation, or favoring by the United States Government or the University of California. The views and opinions of authors expressed herein do not necessarily state or reflect those of the United States Government or the University of California, and shall not be used for advertising or product endorsement purposes. 


\section{EBIT X-ray Spectroscopy Studies for Applications to Photo-Pumped X-ray Iaseas}

S. R Elliott, P. Beiersdorfer, and J. Nilsen

Lawrence Livermore National Laboratory

Livermore, CA 94550

Introduction Several pumping mechanisms have been suggested for $x$-ray lasers induding collisional excitation, recombination, photo-ionization and photopumping [1]. The success of photo-pumping as an $x$-ray laser scheme hinges on sufficient overlap of the emission and absorption lines. For such a scheme to exhibit gain, the difference of the energies of the two lines must be within the line widths determined by the plasma dynamics, such as Doppler and opacity broadening. Typically, an overlap of a few parts in $10^{4}$ is required. Due to correlation effects, high-n levels of multi-electron ions are difficult to calculate and are reliable to roughly a part in $10^{3}$. These differences are large enough to preclude accurate predictions of sucoessful overlaps. As a result, precise measurements of the overlaps are needed. The continued interest in photopumping schemes lies in its potential to improve the laser output. It also allows the excitation of lasing transitions not accessible to other mechanisms and thus to test laser kinetics from a different perspective. Figure 1 shows an example of a photo-pumped $x$-ray laser scheme.

We have studied several such photo-pumping schemes at the LLNL electron beam ion trap (EBIT)[2]. The Ni-like isoelectronic sequence $3 d-5 f$ and $3 d-$ 6f transitions were studied for photo-pumping by He-like ions, the Ne-like $2 \mathrm{p}-4 \mathrm{~d}$ transitions were studied for photo-pumping by $\mathrm{Ni}$-like $3 \mathrm{~d}-4 \mathrm{f}$ transitions, and $\mathrm{Ni}$ like $3 d_{5 / 2}-6 f_{7 / 2}$ transitions.were studied for photo-pumping by H-like Ly- $\alpha$ transitions. A number of other chance caincidence pairs which do not follow an isoelectronic sequence were also studied. The data were taken with a flat-crystal vacuum spectrometer [3], a flat-crystal helium atmosphere spectrometer, or a curved-crystal spectrometer in the von Hamos geometry[4].

The advantage of EBIT over laser-produced or tokamak plasmas for such experiments is its ability to control the charge balanœ and the excitation process. By choosing the electron beam energy, we can select a dominant charge state In particular, by operating below various icnization potentials, the contributions of various charge states to a spectrum can be deduced. Moreover, blends with satellite lines produced by dielectronic recombination can be avoided by proper choic of the beam energy. Thus, wavelength measurements are unambiguous, reliable, and precise.

Nitike ions pump Ne like ions We have investigated a particular dass of schemes whereby a $2 \mathrm{p}_{1} / 2-4 \mathrm{~d}_{3 / 2}$ transition in a Ne-like ion of atomic number $Z$ is photo-pumped by a $3 \mathrm{~d}_{5 / 2}-4 \mathrm{f}_{7 / 2}$ transition in a corresponding Ni-like ion of atomic number $(2 Z+5)[5]$. These potential resonances lie along an isoelectronic sequence. Therefore we measured a number of the transitions along the sequence to search for good overlap candidates. The theoretical predictions of the energies of these transitions, based on a multi-configuration Dirac-Fock calculation using 
the code of Grant et al. [6], were found to be offset by $1.88 \mathrm{eV}$ from the measured values. By having observed a family of these transitions, the determined offset improves future predictive power.

A similar class of schemes exists where the $2 \mathrm{p}_{1 / 2}-4 \mathrm{~d}_{3 / 2}$ transition in a $\mathrm{Ne}$ like ion of atomic number $Z$ is photo-pumped by the $3 d_{3 / 2}-4 f_{5 / 2}$ transition in a corresponding Ni-like ion of atomic number $(2 Z+4)$. Here the offset was determined to be $2.86 \mathrm{eV}$ and a favorable resonance was identified with Ne-like $\mathrm{Rb}$ pumped by $\mathrm{Ni}$-like $\mathrm{Pt}$ at $2512 \mathrm{eV}$. The energy difference was found to be $0.4 \pm$ $0.1 \mathrm{eV}$ or $160 \mathrm{ppm}$.

Helike ions pump Nitike ions This class of schemes also follows an isoelectronic sequence. The He-like ${ }^{1} \mathrm{P}_{1}-1^{1} \mathrm{~S}_{0}$ transition may pump a $3 \mathrm{~d}-6 \mathrm{f}$ or $3 \mathrm{~d}$ $5 f$ transition in a Ni-like ion. Which transition depends upon the ion pair in question. For this data we also measured an offset between theory and experiment for the Ni-like transitions and found that the $30_{5 / 2}-6 f_{7 / 2}$ transition differed from theary by $1.60 \mathrm{eV}$, the $3 \mathrm{~d}_{3 / 2}-6 \mathrm{f}_{5 / 2}$ transition differs from theory by $2.01 \mathrm{eV}$, the $3 \mathrm{~d}_{5 / 2}-5 \mathrm{f}_{7 / 2}$ transition differs by $1.06 \mathrm{eV}$, and the $3 \mathrm{~d}_{3 / 2}-5 \mathrm{f}_{5 / 2}$ transition differs by $1.29 \mathrm{eV}[7]$. The most favorable overlap was found for the He-like $F$ ${ }^{1} \mathrm{P}_{1}-{ }^{1} \mathrm{~S}_{\mathrm{O}}$ transition pumping the $\mathrm{Ni}$-like $\mathrm{Ag} 3 \mathrm{~d}_{3 / 2}-6 \mathrm{f5} / 2$ transition. The two lines differ by 190 ppm at $738 \mathrm{eV}$.

HHike ions pump Ne-iike and N-iike ions The collection of possible lasantpump pairs in this group do not follow an isoelectronic sequence but are chance coincidences between the H-like Ly- $\alpha$ line and various transitions in a number of Ne-like ions. The pairs we have studied to date are $\mathrm{Ne}$ and $\mathrm{Fe}$ [8], $\mathrm{Na}$ and $\mathrm{Co}$ [9], and $\mathrm{Mg}$ and $\mathrm{Ge}[10]$. The $\mathrm{H}-$ like $\mathrm{Ne} \mathrm{Ly}-\alpha$ and $2 \mathrm{p}_{1 / 2}-4 \mathrm{~d}_{3 / 2} \mathrm{Ne}-\mathrm{like} \mathrm{Fe}$ transitions differ by $600 \mathrm{ppm}$ at $1022 \mathrm{eV}$, the H-like Ly- $\alpha \mathrm{Na}$ and $2 \mathrm{~s}_{1} / 2-4 \mathrm{p}_{3} / 2 \mathrm{Ne}$-like $\mathrm{Co}$ transitions differ by $100 \mathrm{ppm}$ at $1237 \mathrm{eV}$, and the $\mathrm{H}$-like $\mathrm{Ly}-\alpha \mathrm{Mg}$ and $2 \mathrm{~s}_{1 / 2}-3 \mathrm{p}_{1 / 2}$ Ne-like Ge transitions differ by $340 \mathrm{ppm}$ at $1472 \mathrm{eV}$. Figure 2 shows an example of the spectra of $\mathrm{Na}$ and $\mathrm{Co}$ elucidating the overlap.

A measurement was also done on the $\mathrm{H}$-like $\mathrm{Al}$ and $\mathrm{Ni}$-like $\mathrm{Er}$ pair. The $\mathrm{H}$-like $\mathrm{Al} \mathrm{Ly}$-a and $3 \mathrm{~d}_{3 / 2}-4 f_{5 / 2} \mathrm{Ni}$-like Er transitions differ by $1000 \mathrm{ppm}$ at 1726 $\mathrm{eV}[11]$.

An additional class of Ly- $\alpha$ pumped schemes uses a $\mathrm{H}$-like ion of atomic number $Z$ and the $3 d_{5 / 2}-6 f_{7 / 2}$ Ni-like transition in ions of atomic number $(3 Z+21)[12]$. The best candidate was determined to be $\mathrm{H}$-like $\mathrm{Ca}$ pumping $\mathrm{Ni}$ like $\mathrm{Tl}$. The Ca Ly- $\alpha$ and Ni-like $\mathrm{T1} 3 \mathrm{~d}_{5 / 2}-6 f_{7 / 2}$ transitions differ by $260 \mathrm{ppm}$ at $4108 \mathrm{eV}$.

He-like ions pump Nelike ions This collection of possible lasant-pump pairs does not follow an isoelectronic sequence. The pairs we have studied to date include $\mathrm{Ar}$ and $Y$ [13] and $\mathrm{Mg}$ and $\mathrm{Cu}[8]$. The He-like $\operatorname{Ar} 2^{1} \mathrm{P}_{1}{ }^{-1}{ }^{1} \mathrm{~S}_{0}$ and Ne-like $Y$ $3 \mathrm{p}_{1 / 2}-5 \mathrm{~d}_{3 / 2}$ transitions differ by $150 \mathrm{ppm}$ at $3140 \mathrm{eV}$ and the He-like $\mathrm{Mg}{ }^{3} \mathrm{P}_{1}$ ${ }_{1}^{1} \mathrm{~S}_{0}$ and Ne-like $\mathrm{Cu} 2 \mathrm{p}_{3} / 2-4 \mathrm{~d}_{5} / 2$ transitions differ by $200 \mathrm{ppm}$ at $1343 \mathrm{eV}$. Figure 3 shows an example of the spectra of $\mathrm{Mg}$ and $\mathrm{Cu}$. 
Condusion Several of the above pairs are good candidates for photo-pumping. For example, if the appropriate plasma conditions could be prepared, the $\mathrm{Pt}-\mathrm{Rb}$ scheme described above would lase on a transition of about $165 \AA$ The Ar-Y scheme would lase on a transition near $155 \AA$ and the $\mathrm{Mg}-\mathrm{Cu}$ scheme would lase near $235 \AA$

Adknowiedgments This work was perfarmed under the auspices of the U. S. department of Energy by Lawrence Livermore National Laboratory under contract W-7405-Eng-48.

\section{References}

[1] R C. Elton, X ray Lasers, (Academic Press, Inc, San Diega 1990) pp 99 - 198.

[2] M A Levine at a., Physica Scripta T22, 157 (1988); and R E. Marrs \& a., Phys. Rev. Lett. 60, 1715 (1988).

[3] P. Beiersdorfer, and B. J. Wargelin, Rev. Sci. Instrum 65 (1), 13 (1994).

[4] P. Beiersdorfer at al., Rev. Sci. Instrum 61 (9), 2338 (1990).

[5] S. Elliott, P. Beiersdorfer, and J. Nilsen, Phys. Rev. AM7, 1403 (1993).

[6] I P. Grant et al., Comput. Phys. Commun. 21, 207 (1980).

[7] S. Elliott, P. Beiersdorfer, and J. Nilsen, Physica Scripta, In Press.

[8] P. Beiersdarfer, S. R Elliott, and J. Nilsen, Phys. Rev. A9, 3123 (1994).

[9] Joeseph Nilsen, S. R Elliott, and P. Beiersdorfer, To Be Submitted.

[10] J. Nilsen, et al, Submitted to Phys. Rev. A

[11] In Preparation.

[12] P. Beiersdorfer at., Phys. Rev. A46 R25 (1992).

[13] J. Nilsen \& a., Physica Soripta 47, 42 (1993). 


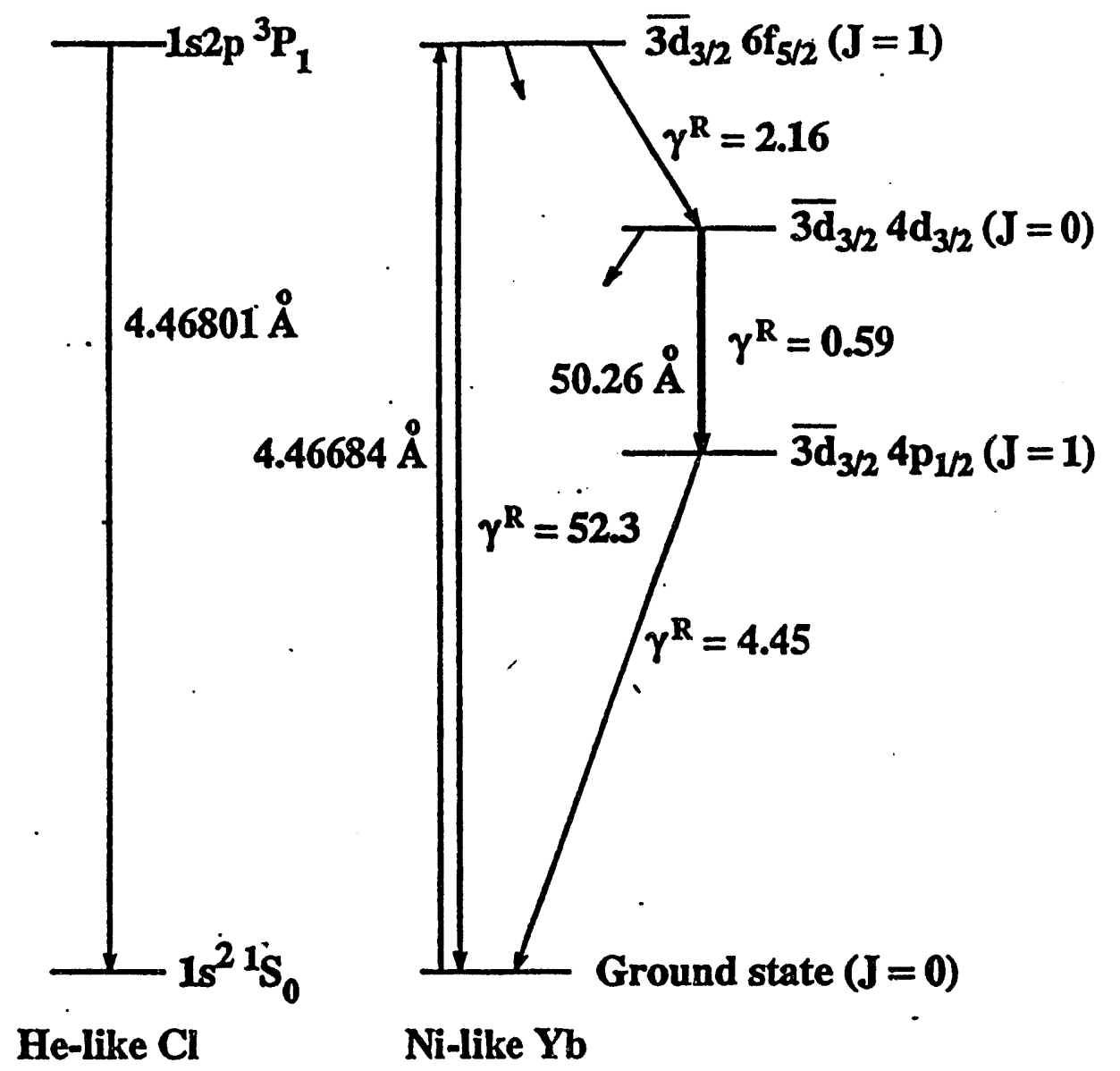

Figures 1: Level diagrams demonstrating an example laser scheme Transition rates are incicated $\gamma^{R}$ and are in units of psect. The bar over the $3 d$ indicates a vacancy in the closed $M$ shell. 


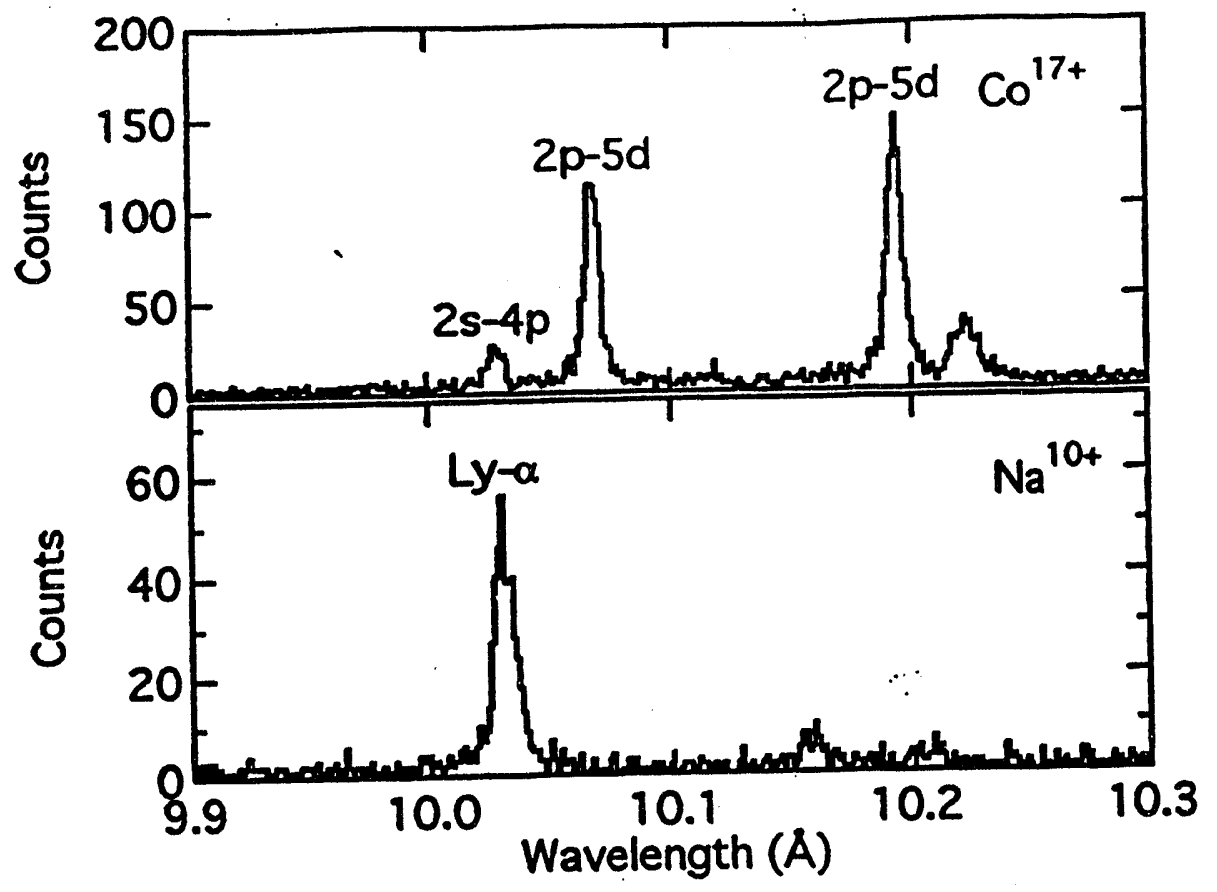

Figure 2: The spectra of H-like $\mathrm{Na}$ and Ne-like Co elucidating the potential overlap.

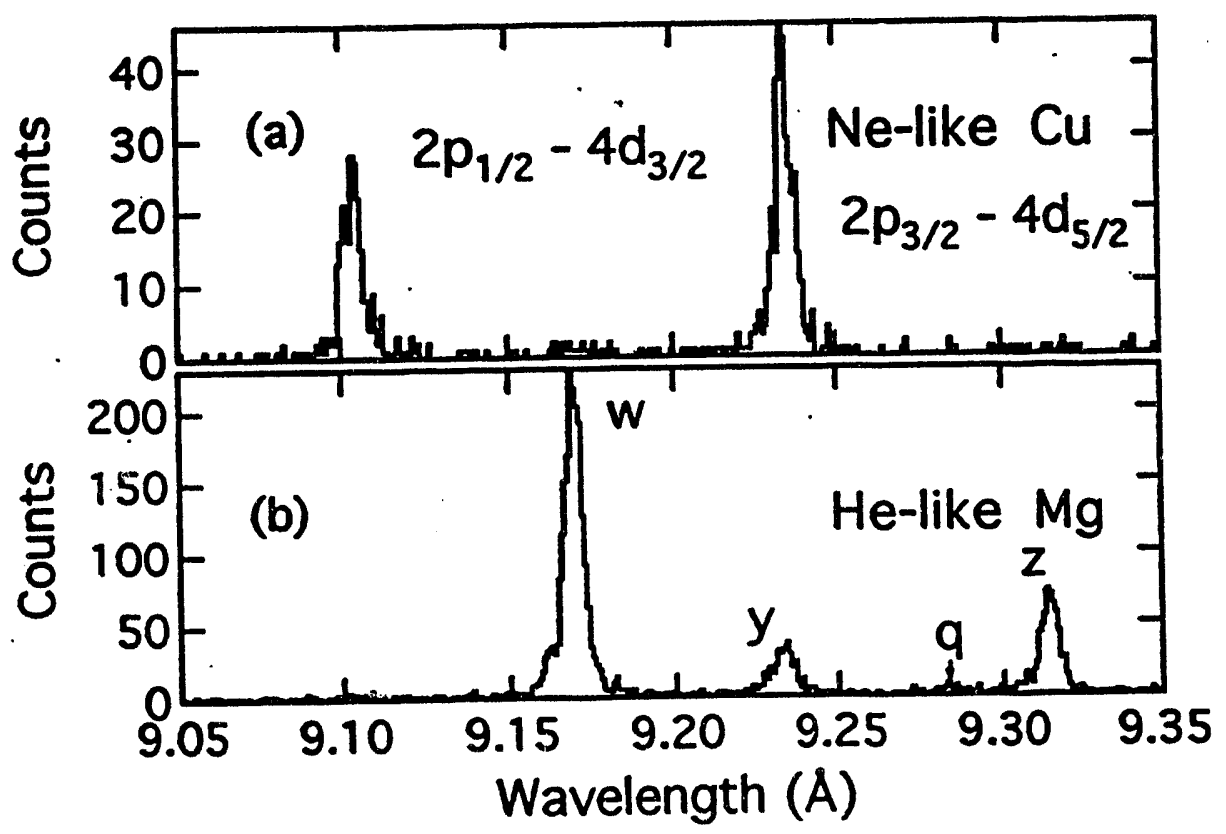

Figure 3: The spectra of He-like $\mathrm{Mg}$ and Ne-like $\mathrm{Cu}$ elucidating the potential overlap. 

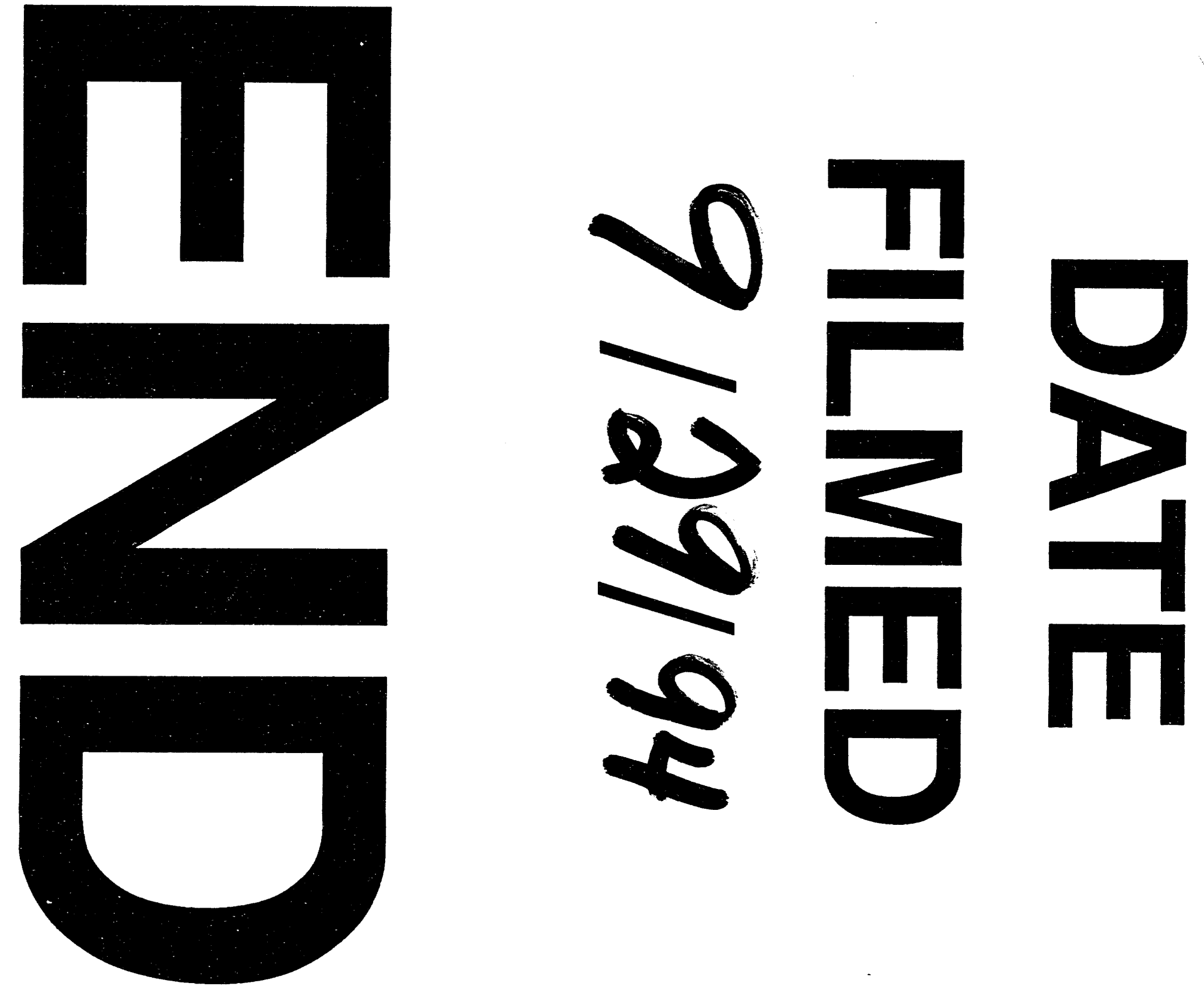


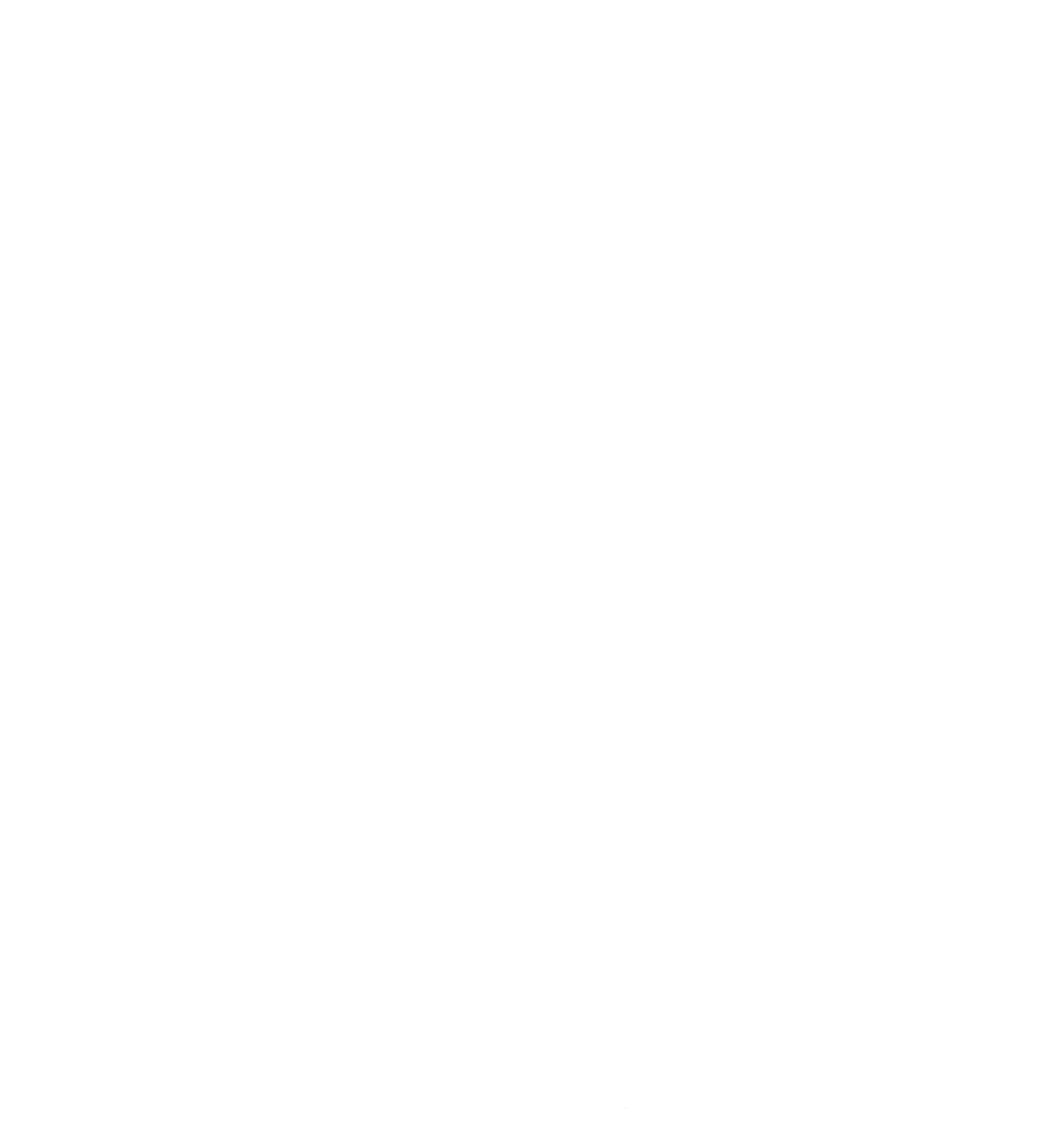

